Original Article

\title{
CARVEDILOL AND NEBIVOLOL PROTECT THE KIDNEY AGAINST RENAL ISCHEMIA IN WISTAR RATS.
}

\section{Amira M Abdelhamid ${ }^{1}$, Ali A Moustafa ${ }^{1}$, Amin M Sekinah ${ }^{1}$, Noha A T Abbas ${ }^{1}$, Hayam E Rashed ${ }^{2}$, Samia Hussein ${ }^{3}$}

1Clinical Pharmacology Department, Faculty of Medicine, Zagazig University, Egypt

2 Pathology Department, Faculty of Medicine, Zagazig University, Egypt

3Mediical Biochemistry Department, Faculty of Medicine, Zagazig University, Egypt

Corresponding Author :

Amira Mohamed

Abdelhamid

Clinical Pharmacology

Department, Faculty of

Medicine, Zagazig

University, Egypt

dr_mero_1985@yahoo.com.

$\begin{array}{ll}\text { Submit Date } & 2019-01-31 \\ \text { Revise Date } & 2019-02-19 \\ \text { Accept Date } & 2019-02-20\end{array}$

\section{ABSTRACT}

Background: Classical $\beta$-blockers usually reduce renal blood flow thus, worsening renal function in hypertensive patients with renal impairment. However, vasodilator $\beta$-blockers with biased agonist activity on $\beta$-arrestin, at least theoretically, could protect the kidney against ischemia. Objectives: To compare the effect of prophylactic administration of carvedilol, nebivolol, nadolol on the kidneys.

Materials \& Methods: Rats were divided into five groups: Group1: shamoperated; Group2: Untreated hypertensive; Group3: Carvedilol pre-treated; Group4: Nebivolol pre-treated; Group5: Nadolol pre-treated. MABP, serum urea, creatinine, renal level of TNF $\alpha, B A X$ and $p E R K 1 / 2$ to non-pERK1/2 ratio were measured, besides renal histopathology and Bax immunohistochemistry.

Results: In carvedilol and nebivolol groups, MABP, Bax, TNF $\alpha$ and pERK1/2 to non-pERK1/2 ratio were not only significantly $(\mathrm{P}<0.05)$ lower than that of the untreated group; but also, not significantly different from that of the sham; except significantly higher pERK1/2 to non-pERK1/2 ratio. In the nadolol pre-treated rats, MABP and the pERK1/2 to nonpERK1/2 ratio were significantly lower than that of the untreated hypertensive rats, however, they were significantly higher than that of the carvedilol, nebivolol pre-treated groups and the sham-operated group. Furthermore, Bax and TNF $\alpha$ were not significantly different from that of the untreated hypertensive group; in the meantime, they were significantly higher compared to sham, carvedilol and nebivolol pretreated groups. Serum urea\& creatinine levels were significantly higher in nadolol pretreated group compared to other groups. Conclusion: Carvedilol and nebivolol have renal protective effect which is nearly equal in contrast to the deterioration caused by nadolol.

Keywords: Renal artery ligation, hypertension, carvedilol, nebivolol, nadolol.

\section{INTRODUCTION}

R-blockers were considered a first line treatment of hypertension for long time, however, recently they displaced to the fourth line choice due to the increased incidence of type-2 diabetes mellitus associated with the chronic use of these drugs ${ }^{[1]}$. The later effect could be attributed not only for the metabolic effect of $\beta$-blockers, but also it could be due to deleterious effect on the pancreatic $\square \square$ cell mass and/or function most probably caused by blocking of the $\beta$ arrestin signaling pathway of $\beta$ adrenoreceptor ${ }^{[2]}$. systemic hypertension has been found to hasten the occurrence of renal disease ${ }^{[3]}$ and $\beta$-blockers reduce both cardiac output and renal blood flow leading to worsening of renal function when administered in hypertensive patients with renal impairment [4]. Carvedilol is shown to reduce blood 
pressure with improvement of renal function, in contrary to the pure $\beta$-blockers ${ }^{[3]}$.

Carvedilol is a nonselective third generation $\beta$-adrenoceptor antagonist with biased agonist effect on $\beta$-arrestin pathway having the characteristic signaling profile of negative efficacy for Gs-dependent adenyl-cyclase activation but positive efficacy for $\beta$-arrestindependent ERK 1/2 activation. B-arrestin acts as scaffold activating signaling networks including ERK 1/2 independent of $G$ protein activity. Thus, carvedilol may have elevated therapeutic benefit over traditional $\square \square$ blockers [5]. In addition, it acts as a selective $\alpha 1$ adrenoceptor antagonist, and exhibits additional effects on ameliorating oxidative stress and inflammation. Activation of ERK supports mitosis, growth and differentiation, whereas JNK and p38 are considered to induce the opposite effects, apoptosis, necrosis, inflammation and fibrosis. The balance of the mentioned key protein kinases decides the further fate of the cell ${ }^{[6]}$.

Nebivolol is a third-generation, long-acting and highly selective $\beta 1$ adrenergic blocker with distinct pharmacodynamic properties compared with other beta blockers having beneficial metabolic effects with a very low rate of side effects ${ }^{[7]}$. Recently, nebivolol approved to act as biased agonist on the $\beta$ arrestin pathway of $\beta 2$-adrenocetor ${ }^{[8]}$.

Since it has been found that hypertension is a risk factor contributing to acceleration of renal disease and reduction of BP could protect for this effect; therefore, it is important to investigate members of $\beta$-blockers, expected to show more renoprotective effect beyond just BP lowering effect. So, the aim of the present study was to compare the effect of carvedilol and nebivolol versus nadolol on the kidneys.

\section{MATERIALS \& METHODS}

\section{Animals:}

35 adult Male Wistar rats weighing 200-250 gm purchased from the animal house of Faculty of Veterinary Medicine, Zagazig University, Egypt were used in the present study. All experiments in this study were performed in accordance with the guidelines for Animal
Research from the National Research Center, Cairo, Egypt. The study protocol was approved by the ethical committee of Zagazig University. The environmental conditions were standardized so that the climate conditions were that of room temperature. Before starting experiments all animals were subjected to 14 days period of adaptation to the new environment. Non-healthy, hypertensive rats or rats weighing below 200 gm were excluded.

\section{Experimental design:}

Rats were randomly divided into five groups, each containing (7) rats: Group (I): Sham-operated, received 1\% DMSO; Group (II): Untreated renal hypertensive, received $1 \%$ DMSO; Group (III): Carvedilol pre-treated (20 mg/kg, dissolved in 1\% DMSO) ${ }^{\text {9] }}$; Group (IV): Nebivolol pre-treated $(10 \mathrm{mg} / \mathrm{kg}$, dissolved in 1\% DMSO) ${ }^{[10]}$; Group (V): Nadolol pre-treated $(50 \mathrm{mg} / \mathrm{kg}$, dissolved in distilled water) ${ }^{[11]}$. Hypertension was induced in rats by persistent complete left renal artery ligation. The animal is considered hypertensive if systolic BP is more than $160 \mathrm{mmHg}$, 28days following renal artery ligation ${ }^{[12]}$. Sham operated rats were subjected to the same previous procedure, except renal artery ligation. All the previous drugs were given once daily through mouth gavage, 5 days before the operation and then continued to the end of the experiment for 28 days after the operation. The rats were sacrificed 28 days after the operation. The animals which did not develop hypertension were excluded. Carvedilol and nebivolol powders were purchased from Marcyrl Pharmaceutical Industries, El Obour City, Egypt. Nadolol, powder was purchased from pharma inc, Toronto, Canada.

\section{Hemodynamic parameters:}

Measurement of blood pressure was performed weekly after the operation by tail cuff plethysmography (8-Channel Non-Invasive Blood Pressure Monitor (NIBP-8) USA).

Biochemical studies:

Blood samples were obtained at the end of the experiments for biochemical studies by means of capillary glass tubing from retroorbital plexus of rats under diethyl-ether 
anesthesia ${ }^{[13]}$. Blood samples were incubated at $37 \mathrm{C}$ until clotted and then centrifuged to separate the sera for measurement of serum urea ${ }^{[14]}$ (The kits were from BioMerieus Laboratory reagents and products) and creatinine $^{[15]}$ (The kits were from Bohringer Gm Bh Diagnostica). Subsequently, rats were sacrificed and the right kidneys were dissected out with coronal transection into two parts. The first part was used for histopathological studies, the remainder was immersed immediately in liquid nitrogen and kept at $-80{ }^{\circ} \mathrm{C}$ and then homogenized, centrifuged and the supernatant was used for measurement of tissue content of BAX, TNF- $\alpha$ and pERK1/2 to non-pERK1/2 ratio using Rat Enzyme-linked immunosorbent assay (ELISA) kits supplied by Sunred biotechnology company, Shanghai, China.

\section{Renal histopathological studies:}

The kidney tissue was fixed in a $10 \%$ neutral buffered formalin solution, embedded in paraffin and used for histopathological examination. $5 \mu \mathrm{m}$ thick sections were cut, deparaffinized, hydrated and stained with hematoxylin and eosin. Samples were examined in a blinded fashion by light microscope for necrosis in the tubular epithelium, tubular dilatation, interstitial inflammation and fibrosis. If all of the above were absent, the sample was graded as $(-)$. If any were present, the sample was graded as mild $(+)$, moderate $(++)$, or severe $(+++)$, depending on the degree of involvement ${ }^{[16]}$.

Statistical analysis: Results were presented as means \pm SE. Comparison between different groups were made using one-way analysis of variances (one-way ANOVA) followed by Post-Hoc (least significant difference "LSD") tests. Chi Square test was also used. The differences were considered to be significant when $\mathrm{p}<0.05$. Statistical Package of Social Sciences (SPSS) (version 16) was used.

\section{RESULTS}

Effect on Blood pressure: (Table 1)

The MABP in the untreated hypertensive rats $(134.8 \pm 1.46 \mathrm{mmHg}), 28$ days after the operation was significantly higher than that of the sham-operated group $(\mathbf{1 0 4}+\mathbf{1} . \mathbf{8 2 7} \mathrm{mmHg})$. In the carvedilol and nebivolol pre-treated rats, the MABP $(\mathbf{1 0 5 . 3} \pm \mathbf{8 . 8 0 6}, \mathbf{1 0 8} \pm \mathbf{2 . 6 5 7} \mathrm{mmHg}$, respectively) were significantly lower than that of the untreated hypertensive rats and insignificantly different from each other and that of the sham-operated group. In the nadolol pre-treated group, the MABP was $118 \pm 4.188$ $\mathrm{mmHg}$, although this value was significantly lower than that of the untreated hypertensive group, it was significantly higher than that in the carvedilol and nebivolol pre-treated and sham-operated groups.

Effect on serum urea and creatinine: (table 2)

The serum urea level, 28 days after the operation, in the sham-operated, untreated hypertensive, carvedilol and nebivolol pretreated groups $(\mathbf{6 4 . 1 2} \pm 3.18, \quad 67.94 \pm 2.047$, $68.82 \pm 5.19,64.64 \pm 5.28 \mathrm{mg} / \mathrm{dl}$, respectively) were insignificantly different from each other's. In nadolol pre-treated group, the serum urea $(\mathbf{1 0 1 . 7 6} \pm 7.46 \mathrm{mg} / \mathrm{dl})$ was significantly $(\mathrm{p}>0.05)$ higher than that determined in any of the other groups.

The serum creatinine level in the shamoperated, untreated hypertensive, carvedilol and nebivolol pre-treated groups $(\mathbf{0 . 7 3 + 0 . 0 1 5}$, $0.788 \pm 0.014,0.73 \pm .019$ and $0.74 \pm 0.012 \mathrm{mg} / \mathrm{dl}$, respectively) were insignificantly different from each other's. In the nadolol pre-treated group, serum creatinine $(\mathbf{0 . 8 2} \pm \mathbf{0 . 0 0 6} \mathrm{mg} / \mathrm{dl})$ was significantly higher than that of the shamoperated, carvedilol pre-treated, and nebivolol pre-treated groups. However, it was insignificantly different from that of the untreated hypertensive group.

Effect on kidney tissue level of TNF- $\alpha$ : (table 3)

In the untreated hypertensive rats, TNF- $\alpha$ level $\quad(\mathbf{6 9} \pm \mathbf{5 . 6 2} \mathrm{pg} / \mathrm{ml})$ was significantly $(p<0.05)$ higher than that of the sham-operated group $(\mathbf{2 8} \pm \mathbf{2 . 0 2 5} \mathrm{pg} / \mathrm{ml})$. In the carvedilol and nebivolol pre-treated groups the levels $(\mathbf{3 2} \pm \mathbf{2 . 1 9}$ and 24 $\mathbf{2 . 5 2} \mathrm{pg} / \mathrm{ml}$, respectively) were significantly $(\mathrm{P}<0.05)$ lower than that in the untreated hypertensive group and insignificantly different from each other and 
that of the sham-operated group. In nadolol pretreated rats TNF- $\alpha$ level $(\mathbf{6 4 . 8} \pm \mathbf{2 . 5 5} \mathrm{pg} / \mathrm{ml})$ was not significantly different from that in the untreated hypertensive group, however, it was significantly $(\mathrm{P}<0.05)$ higher than that in the sham-operated, carvedilol and nebivolol pretreated groups.

\section{(table 3).}

\section{Effect on kidney tissue level of BAX:}

In the untreated hypertensive group, the BAX level $(\mathbf{1 0 . 5} \pm \mathbf{0 . 2 8} \mathrm{pg} / \mathrm{ml})$ was significantly $(\mathrm{p}<0.05)$ higher in relation to the sham-operated group $(\mathbf{3 . 8} \pm \mathbf{0 . 2 9} \mathrm{pg} / \mathrm{ml})$. In carvedilol and nebivolol pre-treated groups, BAX level was $\mathbf{3 . 4 \pm 0 . 1 8}$ and $\mathbf{4} \pm \mathbf{0 . 1 7 3} \mathrm{pg} / \mathrm{ml}$ respectively, both values were significantly $(\mathrm{P}<0.05)$ lower than that in the untreated group, and there was insignificant difference either between each other's or in relation to the sham. In the nadolol pre-treated rats, BAX level $\mathbf{( 1 0 . 9 \pm 0 . 3 2} \mathrm{pg} / \mathrm{ml})$ was insignificantly different from that in the untreated hypertensive group, meanwhile, it was significantly $(\mathrm{P}<0.05)$ higher than that in either carvedilol and nebivolol pre-treated groups or the sham-operated group.

Effect on kidney tissue ratio of pErk1/2 to non-Erk1/2: (table 3).

The ratio of the pErk1/2 to non-Erk $1 / 2$ in the untreated hypertensive group $(\mathbf{1 . 2 5} \pm \mathbf{0 . 0 5 3})$ was significantly higher compared to the sham- operated group $(\mathbf{0 . 8 6} \pm \mathbf{0 . 0 2 7})$. Although the ratio in carvedilol and nebivolol pre-treated groups $(\mathbf{0 . 9 9} \pm \mathbf{0 . 0 3 9}$ and $0.97 \pm 0.02$, respectively) was significantly higher than that in the sham-operated group; it was significantly $(\mathrm{P}<0.05)$ lower than the untreated hypertensive group and insignificantly different from each other. In nadolol pre-treated group, the ratio

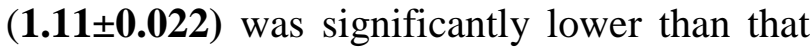
in the untreated hypertensive group. However, it was significantly higher than that in each of the sham-operated, carvedilol, and nebivolol pre-treated groups.

\section{3; figure 1)}

Effect on renal histopathology: (table

In the untreated hypertensive rats, microscopic examination showed enlarged, dilated tubules, marked tubular necrosis and cyst formation, marked interstitial inflammatory infiltrate and marked fibrosis compared with those of the sham-operated group. The severity of these pathological changes was less in the carvedilol and nebivolol pre-treated rats, showing only mild interstitial inflammatory infiltrate in both groups; besides mild tubular necrosis in the carvedilol group. Nadolol pre-treated group showed moderate to marked tubular necrosis and cyst formation, in addition to moderate interstitial inflammatory infiltrate and fibrosis.

\begin{tabular}{|c|c|c|c|c|}
\hline Sham & Untreated hypertensive & Carvedilolpre-treated & Nebivolol pre-treated & Nadolol pre-treated \\
\hline $\begin{array}{l}\text { Renal tissue sections with a } \\
\text { normal morphology from } \\
\text { the sham group showing } \\
\text { normal glomeruli (yellow } \\
\text { arrow) and normal tubule } \\
\text { (black arrow) (H\&E 400). }\end{array}$ & $\begin{array}{l}\text { Renal tissue section with } \\
\text { marked tubular necrosis and } \\
\text { cyst formation (arrow) in the } \\
\text { untreated renal hypertensive } \\
\text { group (H\&E 100). }\end{array}$ & $\begin{array}{l}\text { Renal tissue section with } \\
\text { mild tubular necrosis } \\
\text { (arrow) and mild } \\
\text { interstitial inflammatory } \\
\text { infiltrate of carvedilol pre- } \\
\text { treated group (H\&E 400). }\end{array}$ & $\begin{array}{l}\text { Renal tissue section with } \\
\text { mild interstitial } \\
\text { inflammatory infiltrate of } \\
\text { nebivolol pre-treated group } \\
\text { (H\&E 400). }\end{array}$ & $\begin{array}{l}\text { Renal tissue sections with } \\
\text { moderate tubular necrosis } \\
\text { and cyst formation (arrows) } \\
\text { of nadolol pre-treated group } \\
\text { (H\&E 100) }\end{array}$ \\
\hline
\end{tabular}

Figure 1 Effect on renal histopathological features. 


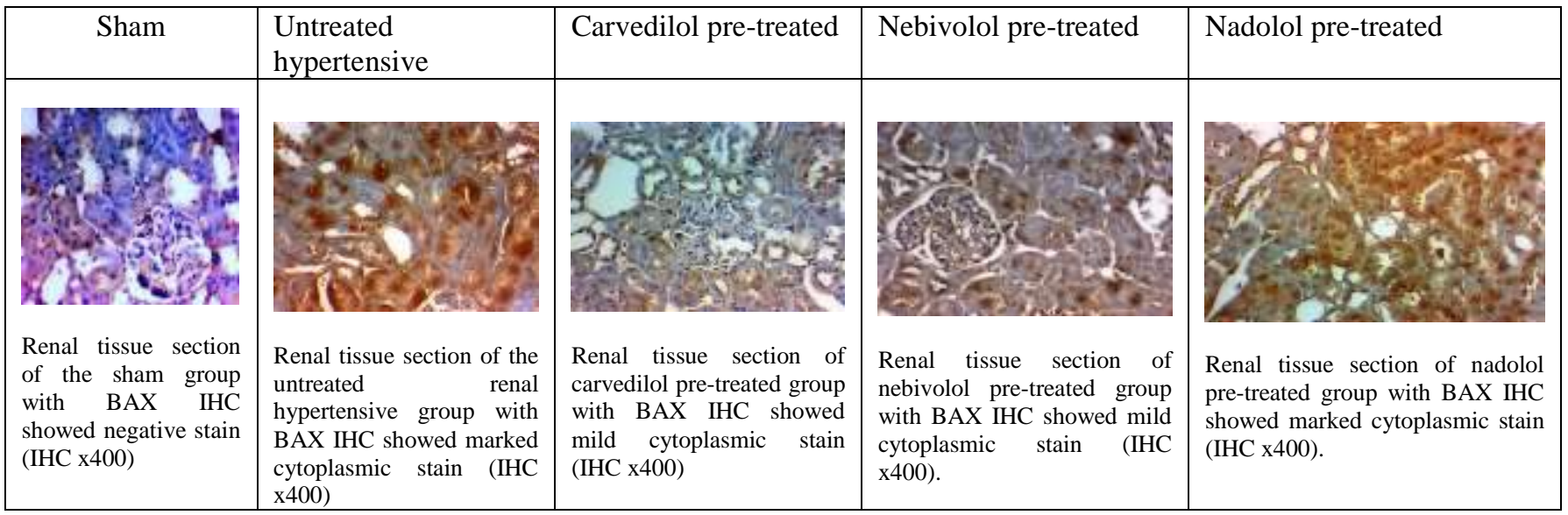

Figure 2 Effects on the renal tissue level of BAX immunohistochemistry expression

Table 1 The changes (mean $\pm \mathrm{SE}$ ) of the MABP $(\mathrm{mmHg})$ and kidney function parameters in different groups:

\begin{tabular}{|l|l|l|l|l|l|}
$\begin{array}{l}\text { Group } \\
\text { Parameter }\end{array}$ & $\begin{array}{c}\text { Sham operated } \\
\text { rats (n=7) }\end{array}$ & $\begin{array}{c}\text { Untreated renal } \\
\text { hypertensive(n=7) }\end{array}$ & $\begin{array}{c}\text { Carvedilol } \\
\text { Pre-treated } \\
(\mathbf{n}=7)\end{array}$ & $\begin{array}{c}\text { Nebivolol } \\
\text { pre-treated } \\
(\mathbf{n}=7)\end{array}$ & $\begin{array}{c}\text { Nadolol pre-treated } \\
(\mathbf{n}=7)\end{array}$ \\
\hline MABP $(\mathbf{m m H g})$ & $104 \pm 1.827^{\mathbf{A}}$ & $134.8 \pm 1.462^{\mathbf{B}}$ & $105.3 \pm 8.806^{\mathbf{A}}$ & $108 \pm 2.657^{\mathbf{A}}$ & $118 \pm 4.188^{\mathbf{C}}$ \\
\hline Serum urea $(\mathbf{m g} / \mathbf{d l})$ & $64.12 \pm 3.18^{\mathbf{A}}$ & $67.94 \pm 2.074^{\mathbf{A}}$ & $68.82 \pm 5.19^{\mathbf{A}}$ & $64.64 \pm 5.28^{\mathbf{A}}$ & $101.76 \pm 7.46^{\mathbf{B}}$ \\
\hline $\begin{array}{l}\text { Serum creatinine } \\
\text { Level }(\mathbf{m g} / \mathbf{d l})\end{array}$ & $0.73 \pm 0.02^{\mathbf{A}}$ & $0.788 \pm 0.01^{\mathbf{A B}}$ & $0.73 \pm 0.02^{\mathrm{A}}$ & $0.74 \pm 0.012^{\mathrm{A}}$ & $0.82 \pm 0.006^{\mathrm{B}}$ \\
\hline
\end{tabular}

- $\mathrm{N}=$ number of animals in each group.

- Within the same row, values without the same superscript capital letter are significantly $(\mathrm{p}<0.05)$ different.

Table 2 The changes (mean \pm SE) of kidney tissue level of TNF $\alpha$ and BAX and pErk1/2 / Total Erk1/2 ratio.

\begin{tabular}{|c|c|c|c|c|c|}
\hline Group Parameter & $\begin{array}{l}\text { Sham } \\
\text { operated rats } \\
(n=7)\end{array}$ & $\begin{array}{l}\text { Untreated renal } \\
\text { hypertensive }(n=7)\end{array}$ & $\begin{array}{l}\text { Carvedilol Pre- } \\
\text { treated }(n=7)\end{array}$ & $\begin{array}{l}\text { Nebivolol pre- } \\
\text { treated }(n=7)\end{array}$ & $\begin{array}{l}\text { Nadolol pre- } \\
\text { treated }(n=7)\end{array}$ \\
\hline TNFa (pg/ml) & $28 \pm 2.025^{A}$ & $69 \pm 5.62^{B}$ & $32 \pm 2.19^{A}$ & $24 \pm 1.52^{A}$ & $64.8 \pm 2.55^{B}$ \\
\hline BAX (pg/ml) & $3.8 \pm 0.29^{A}$ & $10.5 \pm 0.28^{B}$ & $3.4 \pm 0.18^{A}$ & $4 \pm 0.137^{A}$ & $9.9 \pm 0.87^{B}$ \\
\hline $\begin{array}{l}\text { pErk1/2 / Total } \\
\text { Erk1/2 ratio }\end{array}$ & $0.86 \pm 0.027^{A}$ & $1.25 \pm 0.053^{B}$ & $0.99 \pm 0.039^{C}$ & $0.97 \pm 0.02^{C}$ & $1.11 \pm 0.022^{D}$ \\
\hline
\end{tabular}

- $\mathrm{N}=$ number of animals in each group.

- Within the same row, values without the same superscript capital letter are significantly $(\mathrm{p}<0.05)$ different. 
Table 3 Effects on renal tissue level of BAX immunohistochemistry expression.

\begin{tabular}{|c|c|c|c|c|c|c|c|}
\hline $\begin{array}{l}\text { Group } \\
\text { Bax } \\
\text { expression }\end{array}$ & $\begin{array}{l}\text { Sham } \\
\text { operated } \\
\text { rats }(n=7)\end{array}$ & $\begin{array}{l}\text { Untreated renal } \\
\text { hypertensive } \\
(\mathbf{n}=7)\end{array}$ & $\begin{array}{l}\text { Carvedilol } \\
\text { Pre-treated } \\
(\mathrm{n}=7)\end{array}$ & $\begin{array}{l}\text { Nebivolol pre- } \\
\text { treated }(n=7)\end{array}$ & $\begin{array}{l}\text { Nadolol pre- } \\
\text { treated }(n=7)\end{array}$ & $\begin{array}{l}\text { Chi } \\
\text { Square(X }\end{array}$ & $\begin{array}{l}P \\
\text { value }\end{array}$ \\
\hline$-/+$ & 8 & $\mathbf{0}$ & 3 & 2 & $\mathbf{0}$ & 18.864 & 0.001 \\
\hline++ & 1 & 0 & 4 & 5 & 0 & 14.143 & 0.007 \\
\hline+++ & $\mathbf{0}$ & 2 & $\mathbf{0}$ & $\mathbf{0}$ & 3 & 9 & 0.061 \\
\hline ++++ & 0 & 5 & $\mathbf{0}$ & $\mathbf{0}$ & 4 & 17.22 & 0.002 \\
\hline
\end{tabular}

There are significant $(\mathrm{P}<0.05)$ changes between the groups in all grades of BAX immunohistochemistry expression except +++ grade where, there is insignificant change between the groups.

Table 4 Effects on renal tissue histopathological features.

There are significant $(\mathrm{P}<0.05)$ changes between the groups in all pathological changes except ++ grade where, there is insignificant change between the groups.

\begin{tabular}{|l|l|l|l|l|l|l|l|}
\hline $\begin{array}{l}\text { Group } \\
\text { Necrosis, } \\
\text { tubular } \\
\text { dilatation, } \\
\text { interstitiah } \\
\text { inflammation } \\
\text { and fibrosis. }\end{array}$ & $\begin{array}{l}\text { Sham } \\
\text { operated } \\
\text { rats (n=9) }\end{array}$ & $\begin{array}{l}\text { Untreated } \\
\text { renal } \\
\text { hypertensive } \\
(\mathbf{n = 7})\end{array}$ & $\begin{array}{l}\text { Carvedilol } \\
\text { Pre-treated } \\
(\mathrm{n}=7)\end{array}$ & $\begin{array}{l}\text { Nebivolol pre- } \\
\text { treated (n=7) }\end{array}$ & $\begin{array}{l}\text { Nadolol pre- } \\
\text { treated (n=7) }\end{array}$ & $\begin{array}{l}\text { Chi } \\
\text { Square(X } \\
2)\end{array}$ & $\begin{array}{l}\text { P } \\
\text { value }\end{array}$ \\
\hline- & 8 & 0 & 2 & 2 & 0 & 24.545 & 000 \\
\hline+ & 1 & 0 & 4 & 5 & 1 & 14.143 & 0.007 \\
\hline++ & 0 & 2 & 1 & 0 & 3 & 6.538 & 0.162 \\
\hline+++ & 0 & 5 & 0 & 0 & 3 & 16.115 & 0.003 \\
\hline
\end{tabular}

\section{DISCUSSION}

In the present study, the MABP was significantly higher in the untreated rats compared to the sham. This is in agreement with previously demonstrated results ${ }^{[17,18]}$. In the groups pretreated with carvedilol, nebivolol or nadolol, the MABP was significantly lower than that in the untreated hypertensive group, Various mechanisms have been suggested for the antihypertensive effect of $\beta$-blockers: reduction of cardiac output, action on the central nervous system, suppression of renin secretion, and production of vasodilator prostanoids ${ }^{[19]}$. However, the MABP in both carvedilol and nebivolol pre-treated groups was significantly lower than that of nadolol pre- treated group The advantage of these thirdgeneration $\beta$-blocker, carvedilol and nebivolol, over traditional $\beta$-blockers in terms of $\mathrm{BP}$ reduction, is due to their additional direct vasodilatory actions via alpha 1-adrenoceptors blocking and calcium channel-blocking effects of carvedilol and the ability of nebivolol to increase the endogenous production and release of endothelial $\mathrm{NO}^{[7]}$.

The serum urea and creatinine levels, determined 28 days following left renal artery ligation demonstrated insignificant change between the untreated hypertensive and the sham-operated groups. These results are in parallel with the findings of Dias et al. ${ }^{[20]}$, who explained that this is presumably due to a 
compensatory increase in glomerular filtration rate, which appears to be sustained by the contralateral (unclipped) kidney. The serum urea level in the nadolol-pretreated group was significantly higher than that of the shamoperated, the untreated hypertensive, carvedilol and nebivolol pre-treated groups. This was illustrated by Weber and Drayer. ${ }^{[4]}$ who stated that $\square \square$ blockers are usually shown to reduce both cardiac output and renal blood flow resulting in aggravation of renal dysfunction when administered in hypertensive patients with renal impairment. The serum urea and creatinine levels in the carvedilol and nebivolol-pretreated groups were insignificantly different from that in the untreated hypertensive group reflecting the absence of any deleterious effect on the kidney function. Several experimental reports demonstrated that both carvedilol and nebivolol could decrease the elevated serum urea and creatinine in different rat models (Nakamoto et al. ${ }^{[3]}$, Rodriguez-Perez et al. ${ }^{[21]}$ Gandhi et al. [22]

The renal tissues level of TNF- $\alpha$, in the untreated hypertensive group was significantly higher than the sham. This is consistent with Oliveira-Sales et al. ${ }^{[18]}$. The level of TNF $\alpha$ in the carvedilol and nebivolol pre-treated groups was significantly lower than that of the untreated group. The carvedilol and nebivolol anti-inflammatory effects are in line with Liu et al. ${ }^{[23]}$, Gandhi et al. ${ }^{\text {[22] }}$. In nadolol pre-treated group, there was insignificant difference in the level of TNF $\alpha$ compared to the untreated group; this could exclude any anti-inflammatory effect to the drug.

The level of BAX in the untreated hypertensive group was significantly higher compared to the sham-operated group. This is in agreement with Oboshi et al. ${ }^{[24]}$. In the carvedilol and nebivolol pre-treated groups, the levels of BAX were significantly lower than the untreated hypertensive group and nadolol pretreated group, denoting anti-apoptotic effect to both drugs. These finding of the anti-apoptotic effect of carvedilol and nebivolol are corroborated with Arozal et al. ${ }^{[25]}$, Labib et al. ${ }^{[26]}$ and Uzar et al. ${ }^{[27]}$. In nadolol pretreated group, no significant change in the level of BAX in relation to the untreated group, denying any anti-apoptotic effect of the drug.

The kidney $p E r k 1 / 2$ to non-pErk1/2 ratio of the untreated hypertensive rats was significantly higher than that of the shamoperated rats. This was explained by Feliers and Kasinath ${ }^{[28]}$ whom stated that acute or chronic kidney injury results from various insults and pathological conditions, is accompanied by activation of compensatory repair mechanisms. Both insults and repair mechanisms are initiated by circulating factors, whose cellular effects are mediated by activation of two main signal transduction pathways which are the PI-3K (phosphatidylinositol-3-kinase) and the MAPK (Mitogen-activated protein kinase). Immediately following removal of the contralateral kidney, hyperfiltration occurs in the remaining kidney, followed by compensatory growth, which is due to hypertrophy of mostly tubular epithelial cells [29]. Mitogenic growth factors as well as TGF $\beta$ are upregulated in the remaining kidney ${ }^{[28]}$ and Erk plays a crucial role in signaling by mitogenic growth factors; and is important in the first phase of the hypertrophic program. This is a physiological response to the removal of the contralateral kidney. Thus, Erk plays a fundamental role in the development of compensatory kidney growth after unilateral nephrectomy ${ }^{[28]}$. In the carvedilol, nebivolol and nadolol pre-treated groups, the ratios of $\mathrm{pErk} 1 / 2$ to non-pErk1/2 were significantly lower in relation to the untreated hypertensive groups. This may be due to block of the renin angiotensin system which play some role in the hypertrophic program thus preventing angiotensin II-induced ERK1/2 activation and this is in agreement with Shen et al. ${ }^{[30]}$ who reported that pretreatment with metformin prevents renal fibrosis by preventing angiotensin II-induced ERK1/2 activation in angiotensin II-treated renal fibroblast. In the carvedilol and nebivolol pre-treated groups, there was significant decrease in the ratio in 
comparison with nadolol pre-treated group. This may be due to increased renal plasma flow and GFR by causing dilatation in the afferent and efferent arterioles ${ }^{[31]}$, improving the intra renal perfusion therefore, decreasing the pressure on the contralateral kidney and the hypertrophic program.

Microscopic examination showed enlarged, dilated tubules, marked tubular and interstitial inflammatory infiltrate in the untreated hypertensive rats compared with the sham. This was demonstrated by Oboshi et al. [24], Oliveira-Sales et al. ${ }^{[18]}$ who reported that after a critical reduction in functional renal mass, the previously normal nephrons undergo progressive injury over a few weeks to months and that removal of one kidney is known to be associated atrophic glomeruli and interstitial fibrosis in the contralateral kidney. The severity of these pathological changes was less in the carvedilol and nebivolol pre-treated rats. This agree with Nakamoto et al. ${ }^{[3]}$, Cao et al. ${ }^{[9]}$, Moningka et al. ${ }^{\text {[32] }}$

Despite extensive research, the precise roles of different MAPKs in renal pathology, especially in hypoxic/ischemic nephropathy, are still not well understood, and there are major controversies. For example, some studies showed that, activation of ERK1/2 in the human kidney with glomerulopathies correlated with cell proliferation, histologic lesions, renal fibrosis ${ }^{[33]}$, while other work suggests that apoptosis in diabetic rat kidneys is likely related to a decrease in pERK1/2 levels. Most studies suggest ERK1/2 as a mediator of controlling cell survival in response to many stimuli including hypoxia/ischemia in the kidney ${ }^{[34]}$. It is likely that ERK1/2 may have different effects on kidneys, which depends on experimental model, stress type, and many other factors.

\section{CONCLUSION}

Carvedilol and nebivolol blood pressure lowering and renoprotective effect is nearly equal. Carvedilol and nebivolol could be of benefit and recommended in patients with renovascular diseases. However, further experimental and clinical studies are needed to confirm these findings where JNK and p38, the other arms of the MAPK pathway, are needed to be measured.

\section{Declaration of interest}

The authors report no conflicts of interest. The authors alone are responsible for the content and writing of the paper.

Funding information

None declared

\section{REFERENCES}

1- Williams B, Poulter NR, Brown MJ. Guidelines for management of hypertension: report of the fourth working party of the British Hypertension Society, BHS IV. J Hum Hypertens., 2004;18(3):139-185.

2- Zhu L, Almaca J, Dadi P. b-arrestin-2 is an essential regulator of pancreatic b-cell function under physiological and pathophysiological conditions. Nature communications.,2017;8:14295.

3- Nakamoto H. Suzuki H, Katsumata H. Effects of Carvedilol on Renal Function and Blood Pressure in Three-Fifths Nephrectomised Spontaneously Hypertensive Rats Loaded with High Salt. Drugs.,1988;36:160-164.

4- Weber M, Drayer J. Renal effects of betaadrenoceptor blockade. Kidney International., 1980;18:686-699.

5- Wisler JW, DeWire SM, Whalen EJ. A unique mechanism of beta-blocker action: carvedilol stimulates beta-arrestin signaling. Proc Natl Acad Sci USA.,2007;104:16657-16662.

6- Sauvant C, Holzinger H, Gekle M: Inhibition of the Mitogen Activated Protein kinase ERK1/2 Amplifies Ochratoxin A Toxicity in the Proximal Tubule of the Kidney. Mycotoxin Research.,2003;Vol.19.

7- Fongemie J, Felix-Getzik E. A Review of Nebivolol Pharmacology and Clinical Evidence. Drugs., 2015;75:1349-1371.

8- Erickson CE, Gul R, Blessing CP. The b-blocker Nebivolol Is a GRK/b-arrestin Biased Agonist. PLoS ONE.,2013;8(8).

9- Cao G, Gómez H, Ottaviano G. Carvedilol protects the peritubular capillaries and kidney structure in spontaneously hypertensive rats. International Journal of Cardiology.,2015;181:415-416.

10- Varagic J, Ahmad S, Brosnihan B. Salt-Induced Renal Injury in Spontaneously Hypertensive Rats:Effects of Nebivolol. Am J Nephrol.,2010;32:557-566.

11- Lee R, Tsoporis J, Wang R. Influence of chronic nadolol treatment on blood pressure and vascular changes in spontaneously hypertensive rats. Can. J. Physiol. Pharmacol.,1992;70:1261-1278.

12- Cangiano J, sergeant C, Maldonado M. effect of antihypertension treatment on systolic blood pressure and rennin in experintal hypertension in rats. J.Pharmacol.exp.ther.,1978;208:310-313. 
13- Slododa A.E., Birnpaum J.E., Oronsky A.L. Studies on type II collagen-induced polyarthritis in rats. Arthritis Rheum.,1981;24:616-624.

14- Chaney, A.L. and Marbach, E.P. determination of urea by urese-berthelot reaction. Clin.Chem.,1962;8:130-135.

15- Doolan, P.D, Alpen, E.L. and Theil, B.G. a clinical appraisal of the plasma concentration and endogenous clearance of creatinine. AM.J.Med., 1962; 32:65-79.

16- Akgu"llu“ C, Saruhan T, Eryilmaz U. The first histopathological evidence of trimetazidine for the prevention of contrast-induced nephropathy. Ren Fail.,2014;I36:575-580.

17- TARJAN E, FEKETE A. Experimental Renal Hypertension in Rats. International Urology and Nephrology.,1975;7(2):149-156.

18- Oliveira-Sales E, Varela V, Maquigussa E. Renovascular hypertension: Effects of mesenchymal stem cells in the contralateral hypertensive kidney in rats. Clinical and Experimental Hypertension.,2016.

19- Conway J. Hypotensive mechanisms of beta blockers. European Heart Journal.,1983;4:43-51.

20- Dias A, Rodrigues B, Marcella L. Sildenafil ameliorates oxidative stress and DNA damage in the stenotic kidneys in mice with renovascular hypertension. Journal of Translational Medicine.,2014;12(35):9-11.

21- Rodriguez-perez J, Losada A, Anabitarte A. Effects of the Novel Multiple-Action Agent Carvedilol on Severe Nephrosclerosis in Renal Ablated Rats. JPET.,1997;283:336-344.

22- Gandhi C, Zalawadia R, Balaraman R. Nebivolol reduces experimentally induced warm renal ischemia reperfusion injury in rats. Ren Fail.,2008;30:921-930.

23- Liu H, Li W, Gu W. Immunoregulatory Effects of Carvedilol on Rat Experimental Autoimmune Myocarditis. Scandinavian Journal of Immunology.,2010;71: 38-44.

24- Oboshi M, Naito Y, Sawada1 H. Attenuation of hypertension and renal damage in renovascular hypertensive rats by iron restriction. Hypertension Research.,2016;39:832-839.
25- Arozal W, Watanabe K, Veeraveedu P. Protective effect of carvedilol on daunorubicin-induced cardiotoxicity and nephrotoxicity in rats. Toxicology.,2010;274:18-26.

26- Labib DA, Shaker OG, Elfarouk LO. Protective effects of nebivolol on acetic acid-induced ulcerative colitis in rats. Kasr Al Ainy Med J., 2016;22:99-108.

27- Uzar E, Acar A, Evliyaoğlu O. The anti-oxidant and anti-apoptotic effects of nebivolol and zofenopril in a model of cerebral ischemia/reperfusion in rats. Prog Neuropsychopharmacol Biol Psychiatry.,2012;36:2228.

28- Feliers D, Kasinath B: Review Article Erk in Kidney Diseases. Journal of Signal Transduction.,2011; Article ID 768512,p8.

29- Sinuani I, Beberashvili I, Averbukh Z. Mesangial cells initiate compensatory tubular cell hypertrophy. American Journal of Nephrology.,2010;31(4):326331.

30- Shen Y, Miao N, Xu J, Gan X. Metformin Prevents Renal Fibrosis in Mice with Unilateral Ureteral Obstruction and Inhibits Ang II-Induced ECM Production in Renal Fibroblasts. Int $J$ Mol Sci.,2016;17.

31- Akgullu C, Hekim T, Eryllmaz U. The usefulness of carvedilol and nebivolol in preventing contrast nephropathy in rats. Informa Healthcare USA.,2015.

32- Moningka N, Tsarova T, Sasser J: Protective actions of nebivolol on chronic nitric oxide synthase inhibition-induced hypertension and chronic kidney disease in the rat: a comparison with angiotensin II receptor blockade. Nephrol Dial Transplant.,2012;27:913-920.

33- Hassan F, Meduru S, Taguchi K: Carvedilol Enhances Mesenchymal Stem Cell Therapy for Myocardial Infarction via Inhibition of Caspase-3 Expression. JPET., 2012; 343(1):62-71.

34- Jiao Z, Chen J, Liu Y. Role of ERK1/2 and JNK phosphorylation in iodine contrast agent-induced apoptosis in diabetic rat kidneys. Ren Fail.,2015;37:1349-1355. 